\title{
Anti-cancer effects of butyrate: use of micro-array technology to investigate mechanisms
}

\author{
Elizabeth A. Williams*, Jonathan M. Coxhead and John C. Mathers \\ Human Nutrition Research Centre, School of Clinical Medical Sciences, University of Newcastle upon Tyne, \\ Newcastle upon Tyne NE1 7RU, UK
}

\begin{abstract}
Epidemiological evidence suggests that a high intake of resistant starch and NSP protects against colo-rectal cancer. The mechanisms underlying this protection are thought to be mediated by the short-chain fatty acid butyrate, which is present in the colonic lumen in millimolar concentrations as a result of bacterial fermentation of carbohydrates that have resisted digestion in the small intestine. In vitro studies have shown that butyrate displays a host of chemo-preventative properties including increased apoptosis, reduced proliferation, down regulation of angiogenesis, enhanced immunosurveillance and anti-inflammatory effects in colo-rectal cancer cell lines. However, the molecular mechanisms underlying the apparent chemo-preventative actions of butyrate are largely unknown. The evidence supporting the role of butyrate as an anti-cancer agent is reviewed, with particular emphasis on those studies that have attempted to elucidate the mechanism of action of butyrate. Our understanding of the mechanistic action of butyrate and its role in cancer prevention is likely to advance considerably in this post-genomic era with the application of genomic and proteomic technologies. Studies are described that have used gene array and proteomic techniques to investigate the response of colo-rectal cancer cells to butyrate. These pioneering studies illustrate the potential of these technologies to help characterise the molecular responses of the cancer cell to butyrate, and to define the role of butyrate (and other nutrients) in the prevention of colo-rectal cancer.
\end{abstract}

Butyrate: Micro-array techniques: Colo-rectal cancer

Butyrate is an abundant anion in colonic contents where it occurs at concentrations of 2-10 mM (Cummings et al. 1987). As with the other major short-chain fatty acids (acetate and propionate), butyrate is an end product of bacterial fermentation of carbohydrates that have escaped digestion in the small bowel. Higher intakes of these structurally-disparate fermentable carbohydrates, which include resistant starches, NSP and oligosaccharides, are associated with reduced risk of colo-rectal cancer (CRC) (Bingham, 1990; World Cancer Research Fund and the American Institute of Cancer Research, 1997). The mechanisms underlying this putative chemo-preventative effect are poorly understood, but the strongest evidence is based on the anti-neoplastic actions of butyrate. Most of this evidence comes from in vitro studies, but D'Argenio et al. (1996) showed that direct administration of butyrate into the colon of rats treated with the carcinogen azoxymethane reduced the number and size of tumours. The present review summarises the evidence for the tumour-suppressing activity of butyrate (Fig. 1) and indicates the promise offered by transcriptomics (in the form of cDNA microarray technology) and proteomics to help elucidate the mechanism of action of butyrate.

\section{Suppression of cell proliferation}

For at least two decades it has been well established that butyrate in low millimolar concentrations suppresses the growth of a range of animal cells (Prasad \& Sinha, 1976; D'Anna et al. 1980; Kruh, 1982; Wintersberger et al. 1983), including CRC cell lines (Whitehead et al. 1986; Gamet et al. 1992; Siavoshian et al. 1997). Exposure to butyrate results in arrest in the $\mathrm{G}_{1}$ phase of the cell cycle and is associated with the induction of terminal differentiation (Leder \& Leder, 1975; Siavoshian et al. 2000). Progression through the $G_{1}$ phase of the cell cycle requires inactivation of the retinoblastoma protein, a phosphoprotein of $105-114 \mathrm{kDa}$ located in the nucleus (Weinberg, 1995). This inactivation 


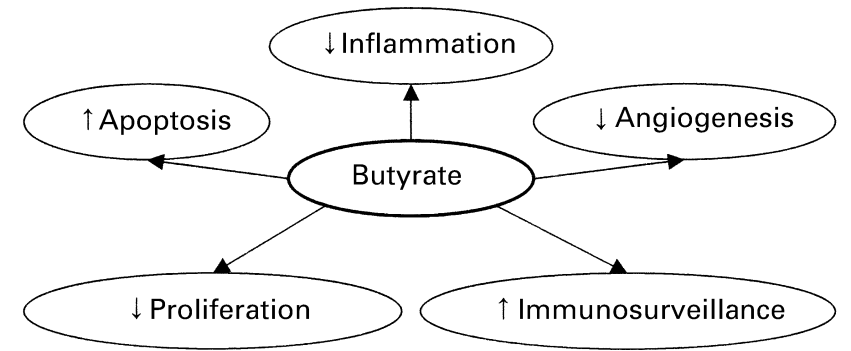

Fig. 1. Potential mechanisms by which the anti-neoplastic actions of butyrate may be mediated.

occurs following phosphorylation of the retinoblastoma protein by cyclin D kinases 4 and 5 and the release of transcription factors, including those of the E2F family. Schwartz et al. (1998) reported that butyrate treatment ( $2 \mathrm{mM}$ for up to $4 \mathrm{~d}$ ) of LS174T colon cancer cells inhibited thymidine kinase activity (required for nucleotide synthesis in the $\mathrm{S}$ phase of the cell cycle) at the same time as inducing dephosphorylation of retinoblastoma protein and resulting in growth arrest. This growth arrest appears to be caused by induction of expression of the cyclin D kinase inhibitor p16 (Schwartz et al. 1998). Butyrate treatment of CRC cells stimulates expression of cyclin D3 (Siavoshian et al. 2000) and of the universal cyclin-dependent kinase inhibitor p21 Waf1/Cip1 (Chai et al. 2000) in a dose-dependent manner (Siavoshian et al. 1997). These increases in cyclin D3 and of p21 have been interpreted as markers of induction of differentiation (Steinman et al. 1994; Kiess et al. 1995). Kruh et al. (1995) reviewed the evidence that differentiation induced by butyrate alters the morphology and ultrastructure of tumour cells, including changes to cell surface mucopolysaccharides and glycolipids, resulting in the loss of most of the malignant characteristics of the cancerous cell.

\section{Induction of apoptosis}

Resistance to death by apoptosis is one of the hallmarks of cancer cells (Hanahan \& Weinberg, 2000) and this factor, together with maintained or enhanced rates of cell proliferation, contributes to expansion of the tumour mass. Hague et al. (1993) were the first to demonstrate that butyrate induced apoptosis in both adenoma and carcinoma cell lines, and reported that this induction of apoptosis was p53independent (see also Mahyar-Roemer \& Roemer, 2001). The latter is particularly interesting because p53 (often described as the 'guardian of the genome') is a transcription factor (Evan \& Littlewood, 1998) that increases in concentration in response to DNA damage and results in growth arrest and repair, or in apoptosis of the damaged cell (Liu \& Kulesz-Martin, 2001). At least $50 \%$ of CRC tumours contain p53 mutations, rendering them susceptible to failure of apoptosis and increased accumulation of DNA damage. Heerdt et al. (1994) confirmed the ability of butyrate to induce apoptosis in colonic tumour cells and proposed that this process occurred via a terminal differentiation pathway. Increased expression of the differentiation markers E-cadherin and alkaline phosphatase was observed in CRC cell lines treated with butyrate (Butt et al. 1997). More recent studies have begun to dissect the molecular mechanisms by which butyrate treatment results in tumour cell apoptosis, and have shown that butyrate up regulates expression of the pro-apoptotic protein BCL-2 homologous antagonist/killer (BAK) and induces caspase-3-mediated cleavage of target proteins, including poly-(ADP-ribose) polymerase (PARP) (Ruemmele et al. 1999; Clarke et al. 2001), the universal cyclin-dependent kinase inhibitor p21 Waf1/Cip1 (Chai et al. 2000) and adenomatous polyposis coli (APC). The latter is cleaved after $\mathrm{Asp}^{777}$ to yield a characteristic and stable $90 \mathrm{kDa}$ fragment (Browne et al. 1994, 1998; Webb et al. 1999).

\section{Anti-inflammatory actions}

Intestinal diseases such as ulcerative colitis and Crohn's disease, which have an important inflammatory component in their pathology, carry an increased risk of CRC. Butyrate has anti-inflammatory effects (Inan et al. 2000; Saemann et al.2000), which may be mediated by interference with the maturation of monocyte-derived dendritic cells (Saemann et al. 2002). Butyrate appears to shift the T helper-1-T helper- 2 balance by inhibiting production of the pro-inflammatory cytokines interleukin (IL) 12 , tumour necrosis factor$\alpha$ and interferon- $\gamma$, whilst having no effect on, or stimulating, the release of IL-6 and IL-10 (Saemann et al. 2000, 2002; Nancey et al. 2002). The molecular mechanism for this shift is unclear, although there is evidence of suppression of nuclear factor kappaB activation in some (Inan et al. 2000) but not all (Diakos et al. 2002) studies. Faust et al. (2001) have argued that the anti-inflammatory actions of butyrate in the intestinal mucosa are unlikely to occur by direct regulation of cytokine-induced anti-inflammatory protein expression. Recent data from Diakos et al. (2002) indicate that at relatively low concentrations $(1 \mathrm{mM})$ butyrate inhibits production of the growth factor IL-2 (which is required for expansion of antigen-specific $T$ cells) by decreasing nuclear binding of the transcription factor nuclear factor of activated $\mathrm{T}$ cells in both Jurkat cells and in primary $\mathrm{T}$ cells.

\section{Up regulation of immunosurveillance}

Although still a controversial concept (for a review, see Armstrong \& Mathers, 2000), it is becoming clearer that some chemo-preventative agents may act by up regulating immunosurveillance. The mechanisms for enhanced immunosurveillance could include better 'visualisation' of tumour cells as foreign by the immune system and/or attenuation of the ability of tumour cells to fight back against immune cells. Perrin et al. (1994) reported that the growth of PROb cancer cells, injected into the peritoneum of rats, was suppressed by concurrent treatment with butyrate and recombinant IL-2. The weak immunogenicity of PROb cells seemed to be enhanced by butyrate treatment making the tumour cells more susceptible to IL-2-activated natural killer cells. Butyrate may increase the effectiveness of other anti-cancer agents, as shown recently for actinomycin D in a mouse melanoma model (Giermasz et al. 2002). Butyrate treatment decreased expression of decay-accelerating factor (DAF) in three colon cancer cells lines (HT-29, Caco-2 and T-84; Andoh et al. 2002). DAF is expressed on the plasma membrane of CRC cells, forming a barrier to complement- 
mediated clearance by the humoral immune response so that down regulation of DAF by butyrate appears to improve immunosurveillance (Andoh et al. 2002). Bonnotte et al. (1998) demonstrated that exposure of several human and rat CRC cell lines to butyrate in vitro increased their sensitivity to Fas ligand-mediated apoptosis in the absence of a change in expression of the Fas receptor on the surface of the target cells.

\section{Down regulation of angiogenesis}

Expansion of solid tumours, including colon carcinomas, requires the production of a new blood supply (neovascularisation). As prevention of neovascularisation will limit the growth of tumours, angiogenesis has become a very attractive target for anti-tumour agents. The cyclooxygenase- 2 selective inhibitor celecoxib, which has been shown to suppress the appearance of colonic polyps in individuals with familial adenomatous polyposis (Steinbach et al. 2000), may act in part via inhibition of angiogenesis. There is now evidence that butyrate may also have antiangiogenic effects. Chemokines and their receptors are involved in angiogenesis, and Jordan et al. (1999) showed that HT-29 cells expressed the chemokine receptor CXCR4. However, within $3 \mathrm{~h}$ of treatment with $5 \mathrm{mM}$-butyrate CXCR4 expression by HT-29 cells was inhibited completely (Jordan et al. 1999). Treatment of the same cell line with $2 \mathrm{mM}$-butyrate down regulated expression of two angiogenesis-related proteins i.e. vascular endothelial growth factor, the most potent angiogenic factor, and hypoxia-inducible factor-1 $\alpha$ (Pellizzaro et al. 2002).

\section{Functional genomics and proteomics}

Over recent years the sequencing of the whole genome of different organisms, including man, has provided the foundation for several powerful new biotechnologies offering insight into: (a) the molecular characteristics of the cell; (b) the regulation of cellular activity; (c) the response of the cell to its environment; (d) cellular defects in disease states. Genomics, transcriptomics and proteomics are all based on the faithful transcription of DNA from the coding region of the gene into a complementary single-stranded mRNA molecule and subsequent translation into the protein (Fig. 2). Application of these technologies is revolutionising the biosciences, but it is in medical sciences where they are likely to have their biggest impact (Mohr et al. 2002). Functional genomics is being used to characterise the molecular events occurring in disease processes (Kitahara et al. 2001; Luo et al. 2001), to identify polymorphisms in genes that may be associated with increased (or decreased) risk of specific diseases (Hacia \& Collins, 1999; Sapolsky et al. 1999) and to search for biomarkers of disease (Van Eyk, 2001; Jones et al. 2002). In addition, these technologies offer exciting opportunities to explore and characterise the mechanistic action of nutrients at a molecular level. The following is a brief overview of the technologies themselves and an indication of how their application has begun to be used to help elucidate the mechanism(s) underlying the antineoplastic action of butyrate.

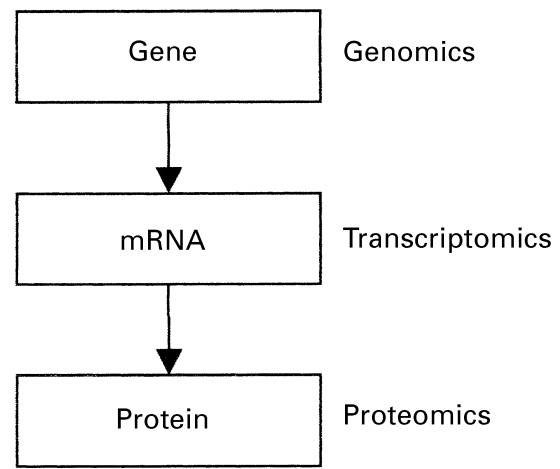

Fig. 2. Relationships between the 'omics' technologies.

\section{Genomics and transcriptomics}

DNA array technology allows the expression of thousands of genes to be analysed simultaneously. This highthroughput approach is facilitating rapid advances in genomics and transcriptomics. The principle underlying the array technologies is hybridisation between complementary single-stranded nucleic acid sequences exploiting the specific relationship between $\mathrm{A}$ and $\mathrm{T}$, and $\mathrm{G}$ and $\mathrm{C}$ (Southern et al. 1999). The latest micro-arrays consist of densely-packed spots of single-strand cDNA or oligonucleotides complementary to the sequence of interest immobilized onto a substrate, e.g. glass or nitrocellulose. mRNA is extracted from cells, reverse-transcribed using fluorescently-labelled nucleotides and hybridised to the array. The array is laser-scanned and expression levels determined from the intensity of the fluorescence at each spot. The results are processed through a database and data mining tools used for analysis (Duggan et al. 1999). Such experiments generate massive amounts of expression data, the interpretation of which is challenging and dependent largely on the quality of genomic databases and of the software tools available. Good experimental design and careful attention to experimental protocols are critical to the success of array experiments. For example, homogeneous populations of cells may be difficult or impossible to extract from heterogeneous biopsy material, so that interpretation of the gene expression data may become equivocal. In addition, without appropriate precautions, less-abundant mRNA may fall below the limits of detection. Array experiments are often complemented by more conventional molecular approaches, e.g. Northern or Western blotting and reverse transcription-polymerase chain reaction to confirm the expression data and/or to investigate the kinetics of expression. mRNA expression does not necessarily correlate with protein expression (Anderson \& Seilhamer, 1997), and does not account for post-translational modification of proteins, so that an integrated approach using transcriptomics and proteomics can provide a powerful insight into cellular activity.

\section{Proteomics}

The term proteome was coined by Wasinger et al. (1995) to describe the protein complement of the genome. Proteomics 
is the study of the protein properties of the cell, encompassing protein expression, protein interactions and post-translational modifications (Blackstock \& Weir, 1999). At the core of the technology is two-dimensional gel electrophoresis, which separates proteins according to molecular weight in one dimension and isoelectric charge in the other (O'Farrell, 1975). The use of large two-dimensional gels allows thousands of protein spots to be resolved in a single gel (Klose, 1999). Gels may be stained using Coomassie blue, silver staining or a fluorescent dye, allowing visualisation of proteins, image analysis and spot detection. The position of a protein spot on the gel may give clues to its identification, but unambiguous protein identification depends largely on MS. For identification a protein spot is selected from the two-dimensional gel, digested with an appropriate protease and its composite peptides identified according to their mass using MS. The pattern of peptide masses provides a unique protein fingerprint that can be used to search protein databases to identify the protein itself. Proteins not identified through this approach are subjected to more advanced MS methods, e.g. matrix-assisted laser desorption-ionisation time-of-flight (MALDI-TOF) allowing partial peptide sequencing. Peptides can then be characterised using nucleic acid sequence databases to search for their sequence tags. Major improvements in MS techniques have led to improved protein identification and detection of post-translational modification which, coupled with the development of protein and nucleic acid databases, have resulted in considerable advances in the field.

\section{Exploring the anti-neoplastic properties of butyrate using functional genomics}

The application of functional genomics to define the mechanisms underlying the neoplastic properties of butyrate has thus far been confined to homogeneous cell cultures. These pioneering studies will be reviewed.

\section{The first in the field}

The first published study that used micro-array technology to investigate the effect of butyrate on the transcriptome of colonocytes was that of Mariadason et al. (2000). The transcriptional response of SW620 colon carcinoma cell line to $5 \mathrm{mM}$-butyrate was compared with responses to three other compounds, i.e. Trichostatin A (TSA; an effective histone deacetylase inhibitor), sulindac (a non-steroidal antiinflammatory drug) and curcumin (a dietary chemoprotective agent). Expression profiles of 8063 gene sequences were analysed using micro-array technology at six time points up to $48 \mathrm{~h}$ post-treatment, and only those genes whose expression, once modified, was sustained until the end of exposure to the agent were included in the analysis. The results demonstrate a complex cascade of reprogramming of SW620 colonic epithelial cells in response to butyrate over time. Genes were recruited rapidly in response to butyrate exposure, with some changes in gene expression observed within $30 \mathrm{~min}$. Subsequent time points were characterised by a progressive expansion of the population of differentially-expressed genes that began to

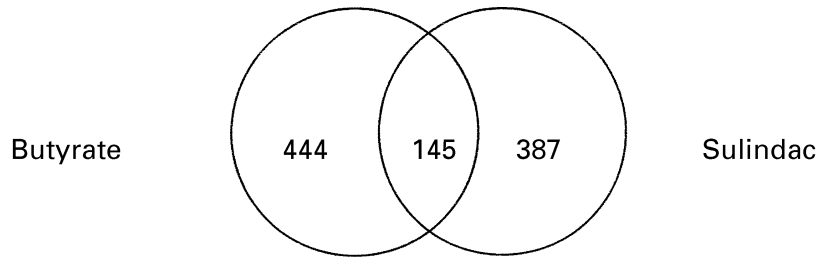

Fig. 3. Summary of the number of genes differentially expressed in SW620 cells following $48 \mathrm{~h}$ exposure to either $5 \mathrm{mM}$-butyrate or $1.6 \mathrm{mM}$-sulindac. (From Mariadason et al. 2000.)

moderate after $16 \mathrm{~h}$. Over the $48 \mathrm{~h}$ a staggering 589 genes were reprogrammed (256 up regulated, 333 down regulated) in the presence of butyrate. Almost as many (534) genes were differentially expressed on exposure to sulindac, with less extensive changes following treatment with TSA and curcumin.

Detailed interrogation of the data showed that, despite the similarities in the phenotypic response of SW620 cells to the butyrate and to the non-steroidal anti-inflammatory drug sulindac, the underlying genetic responses were profoundly different. Both butyrate and sulindac induce $\mathrm{G}_{0}-\mathrm{G}_{1}$ cell cycle arrest, trigger an apoptotic cascade and up regulate $\beta$-catenin- $T$ cell factor. Of the more than 500 genes that were differentially expressed in response to each of the agents, 145 genes were mutually responsive to both butyrate and sulindac exposure (Fig. 3). However, only ninety-two of these genes responded in the same manner to both compounds, with thirty-six up regulated and fifty-six down regulated. The compounds had opposite actions on the remaining fifty-three genes. The genes responsive to butyrate exposure were most comparable with the gene profile evoked by TSA treatment. Butyrate, sulindac and TSA all induce $\mathrm{G}_{0}-\mathrm{G}_{1}$ cell cycle arrest, yet there was more similarity between the cell cycle genes altered in response to butyrate and TSA than in response to sulindac. The greatest differences in response compared with that to butyrate were seen for curcumin, which arrests cells in $\mathrm{G}_{2}-\mathrm{M}$. The authors hypothesised that the activity of butyrate and TSA as histone deacetylase inhibitors could account for the similarity in gene profiles. Both butyrate and TSA inhibited histone deacetylase (observed as an altered acetylated histone H4:histone H1 value, determined by Western blotting), but the kinetics profile of histone hyperacetylation differed for the two agents. These differential kinetics allowed the identification of two clusters of genes (not differentially altered by either sulindac of curcumin) that were activated in tandem with histone acetylation, suggesting that the changes in these genes occur as a consequence of inhibition of histone deacetylase activity. Mariadason et al. (2000) conclude that, in the context of CRC chemo-prevention, agents such as butyrate that induce death of tumour cells by reprogramming them along a 'natural' maturation pathway may offer greater advantages in terms of safety than, for example sulindac, which also induces tumour cell apoptosis but which is associated with side-effects such as mucosal ulceration when used over long periods. In addition, the revelation by micro-array analysis that two agents may induce tumour cell apoptosis by different pathways suggests the possibility of synergy, and opens opportunities for use of combinations of chemo-preventative agents. 


\section{Choosing the most informative time point}

Before deciding on the conditions for an array experiment, Iacomino et al. (2001) confirmed that $4 \mathrm{mM}$-butyrate suppressed cell growth and induced differentiation in the colonic adenocarcinoma cell line HT29. Butyrate-treated cells accumulated in the $G_{1}$ phase of the cell cycle and there was increased expression of the differentiation marker alkaline phosphatase. Protein expression of the cyclindependent kinase inhibitor $\mathrm{p} 21^{\text {Waf1/Cip } 1}$ was elevated, whilst the oncogene c-myc was reduced at $48-72 \mathrm{~h}$. Based on these findings Iacomino et al. (2001) chose to perform their array experiment at $72 \mathrm{~h}$ incubation with butyrate when cell cycle arrest and cell differentiation were maximal. They used an Atlas cDNA array to characterise and quantify the expression of 588 genes, including those involved in cell cycle regulation, signal transduction, apoptosis, DNA synthesis and repair, transcription and the stress response. Of these 588 genes, the HT-29 cells expressed 119, with sixty genes being differentially expressed (thirty-nine up regulated and twenty-one down regulated) in response to butyrate. In this study a twofold change in expression was considered significant. A cluster of genes regulating apoptosis, DNA synthesis, repair and recombination were among those up regulated, whilst a group of oncogenes, cell cycle regulators and transcription factors were down regulated. Reverse transcription-polymerase chain reaction was performed on a random selection of genes to confirm the array results, and on a sub-set of genes that were strongly responsive to butyrate.

Among the interesting findings of this study was the observation that butyrate treatment up regulated expression of a number of genes involved in the detoxification of xenobiotics. This finding suggests that increased butyrate supply to colonocytes might modulate the damage caused by carcinogens and/or alter the sensitivity to anti-tumour drugs. The response of some genes was unexpected, leading the authors to postulate on the role of these genes in the butyrate response. For example, they describe pro- and anti-apoptotic mRNA being concurrently up regulated, a feature that could be explained by deranged activity of cancer cells. In singletime-point micro-array studies such as this study, primary responses to the intervention cannot be distinguished from downstream events, and early events may be missed entirely if they occur transiently in advance of the chosen sampling time point. These possibilities complicate the interpretation of such data.

\section{Focusing on mRNA expression to avoid confounding by downstream events}

Della Ragione et al. (2001) combined aspects of the previous two studies to provide an elegant solution to the problem of downstream events masking the direct effect of butyrate on gene expression. These authors investigated the effects of treatment with butyrate or TSA in the presence of cycloheximide, to inhibit de novo protein synthesis, on the expression profile of HT29 cells. In this way they were able to observe transcriptional effects only. HT29 cells were treated with $2 \mathrm{mM}$-butyrate or $0 \cdot 3 \mu \mathrm{M}$-TSA in the presence of cycloheximide for $5 \mathrm{~h}$. Using the Atlas cDNA array of
588 genes, it was observed that the expression of twentythree genes was modulated in an identical manner (two down regulated and the remainder up regulated) by both butyrate and TSA. Since TSA is a well-characterised histone deacetylase inhibitor, these data provide strong evidence that the initial responses (up to $5 \mathrm{~h}$ after exposure) to butyrate treatment occur via histone deacetylation inhibition.

Increased acetylation of histones would be expected to open up the chromatin structure and to increase transcription (Ballestar \& Esteller, 2002), so the up regulation of expression of twenty-one genes accords with this hypothesis (Della Ragione et al. 2001). What is less clear is the extent to which there is selectivity in this response. In other words, does butyrate treatment lead to a generalised hyperacetylation of DNA? The available evidence obtained using conventional gene expression methods (Kruh et al. 1995) and the more recent micro-array techniques (Mariadason et al. 2000; Della Ragione et al. 2001; Iacomino et al. 2001) suggest that exposure to butyrate up regulates expression of only a relatively small number of genes, but it should be remembered that the cDNA micro-array techniques are insensitive to small changes in expression (usually less than a twofold change).

In the study carried out by Della Ragione et al. (2001) only two of the differentially-expressed genes had been reported to be modulated by butyrate in previous studies. The remainder of the genes, whose functions included cell cycle regulation and DNA repair, may be potentially fruitful areas for further investigations. These authors used Northern blotting and reverse transcription-polymerase chain reaction to confirm mRNA data, and Western blotting to examine protein expression of two genes i.e. Tob-1 (an antiproliferation mediator that acts synergistically with p21) and GATA-2 (a nuclear transcription factor). In addition, they provided direct evidence of the anti-proliferative properties of $T o b-1$ by transfecting HT29 cells with $T o b-1$ cDNA and observing a reduction in $\left[{ }^{3} \mathrm{H}\right]$ thymidine incorporation that correlated with the extent of Tob-1 protein expression.

\section{Concordance between array experiments}

Iacomino et al. (2001) and Della Ragione et al. (2001) both investigated the response of HT29 cells to butyrate exposure using the same ATLAS cDNA array. Of the twenty-three genes induced after $5 \mathrm{~h}$ exposure to $2 \mathrm{mM}$-butyrate in the presence of cycloheximide in the experiment of Della Ragione et al. (2001), eleven were also induced after $72 \mathrm{~h}$ exposure to $4 \mathrm{mM}$-butyrate in the study of Iacomino et al. (2001) (Fig. 4). Of the eleven genes differentially expressed

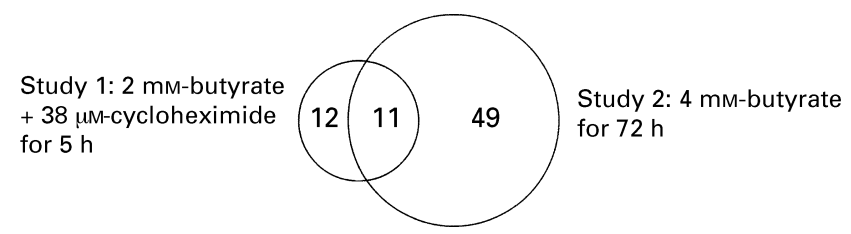

Fig. 4. The number of genes differentially expressed by HT29 cells exposed to butyrate. Study 1, Della Ragione et al. (2001); study 2, lacomino et al. (2001). 
in both experiments nine were up regulated in both studies and two were up regulated after $5 \mathrm{~h}$ (Della Ragione et al. 2001) but down regulated after $72 \mathrm{~h}$ (Iacomino et al. 2001). Whilst aspects of the experimental conditions differed (butyrate concentration, time-frame and use of cycloheximide), the similarities in the gene profiles in response to butyrate (Table 1) offer potential targets for further study.
Several scenarios could explain the differences in gene expression in the two experiments including: (a) genes activated in the absence of cycloheximide may be downstream events; (b) there may be an overall expansion of the number of differentially-expressed genes between 5 and $72 \mathrm{~h}$ (Mariadason et al. 2000); (c) genes may be activated by butyrate in a concentration-dependent manner.

Table 1. Genes in HT29 cells whose expression was modified by butyrate treatment

\begin{tabular}{|c|c|c|c|}
\hline Description & GenBank accession no. & Study* & Direction o \\
\hline \multicolumn{4}{|l|}{ Oncogenes, tumour suppressor and cell cycle control proteins } \\
\hline Cyclin-dependent kinase inhibitor 1A (p21 Cip1) & U09579 & 1 & \\
\hline Growth arrest and DNA damage inducible protein (GADD45) & M60974 & 1 & \\
\hline Lactoferrin delta & U84119 & 1 & \\
\hline Mapkap kinase & U09578 & 1 & \\
\hline Tyrosine protein kinase SKY (TYRO3) & D17517 & 2 & \\
\hline Ezrin & X51521 & 2 & \\
\hline Prothymosin alpha (Pro-T- $\alpha$ ) & M26708 & 2 & \\
\hline SHB adaptor protein (Src homology 2 protein) & X75342 & 2 & \\
\hline CDK4 inhibitor (p16-INK4) & L27211 & 2 & \\
\hline PCNA P120 & X55504 & 2 & \\
\hline V-ERBA-related protein EAR-2 & X12794 & 2 & \\
\hline Urea transporter RACH1 (HUT11) & U35735 & 2 & \\
\hline C-JUN proto-oncogene (JUN) & J04111 & 2 & \\
\hline 40S ribosomal protein $\mathrm{S} 19$ & M81757 & 2 & \\
\hline Proto-oncogene RHOA, multi-drug resistance protein & L25080 & 1 and 2 & \\
\hline TOB-1 & D38305 & 1 and 2 & \\
\hline CD2-related protein kinase PISSLRE & L33264 & 1 and 2 & \\
\hline Cell division control protein (P55CDC) & U05340 & 1 and 2 & \\
\hline
\end{tabular}

Ion channel, stress-response proteins, transport-protein modulators,

effectors and intracellular transducers

Protein kinase $\mathrm{C}$ delta type (PKC $\delta$ )

D10495

Epithelial discoidin domain receptor 1 (TRKE) $\quad$ X74979

Proliferation-associated gene (PAG)

$\mathrm{X} 67951$

TR3 orphan receptor (NAK1)

X67951

Guanine nucleotide regulatory protein (NET1)

U02081

EBI

U24166

Urokinase type plasminogen activator surface receptor (u-PAR) U08839

Extracellular signal-regulated kinase 3 (ERK3)

M80692

p38 Mitogen-activated protein kinase (p53 MAP kinase) L35253

Natural killer cell-enhancing factor B (NKEFB) L19185

Heat-shock protein 40 (HSP40)

D49547

$\begin{array}{ll}\text { cAMP-dependent protein kinase type 1- } \beta \text { regulatory chain } & \text { M65066 } \\ \text { Transducin } \beta-2 \text { subunit } & \text { M36429 }\end{array}$

Tyrosine-protein kinase receptor EPH

M18391

D10924

X54079

Heat-shock $27 \mathrm{kDa}$ protein (HSP27)

Heat-shock $70 \mathrm{kDa}$ protein (HSP70)

Tyrosine-protein kinase receptor EPH-3 (EPHB3)

M11717

X75208

1 and 2

Apoptosis-related proteins, DNA synthesis, repair and recombination proteins

Glutathione S transferase $\theta 1$ (GST-T-1)

Glutathione $S$ transferase $\mathrm{Pi}$ (GST-pi-1)

Glutathione S transferase A1 (GST-A-1)

$\mathrm{X} 15480$

M25627

WSL-LR;WSL-S1;WSL-S2 protein

Y09392

MUTL (E. coli) homologue 1 (hMLH1)

U07418

Defender against cell death 1 (DAD-1)

D15057

Replication factor C. $37 \mathrm{kDa}$ subunit

M87339

Growth factor receptor-bound protein 2 (GRB2) L29511

Cell death protein RIP

U25994

$\begin{array}{ll}\text { Fast kinase (Fas-activated serine-threonine kinase) } & \text { X86779 } \\ \text { Glutathione reductase } & \text { X15722 }\end{array}$

Cytochrome $\mathrm{P} 450$ reductase

S90469

$\begin{array}{rr}1 & \uparrow \\ 1 & \uparrow \\ 1 & \uparrow \\ 1 & \uparrow \\ 1 & \uparrow \\ 1 & \uparrow \\ 2 & \uparrow \\ 2 & \uparrow \\ 2 & \uparrow \\ 2 & \uparrow \\ 2 & \uparrow \\ 2 & \uparrow \\ 2 & \downarrow \\ 2 & \downarrow \\ 1 \text { and 2 } & \uparrow \\ 1 \text { and 2 } & \uparrow \\ 1 \text { and 2 } & \uparrow \\ 1 \text { and 2 } & \uparrow \\ & \end{array}$


Table 1.

\begin{tabular}{|c|c|c|c|}
\hline Description & GenBank accession no. & Study* & Direction of change \\
\hline \multicolumn{4}{|l|}{ DNA binding and transcription factors } \\
\hline Transcriptional regulator ISGF3 $\gamma$ subunit & M87503 & 2 & $\uparrow$ \\
\hline Zinc finger $\mathrm{X}$ chromosomal protein & X59738 & 2 & $\uparrow$ \\
\hline Kruppel-related zinc finger protein HTF10 & $\mathrm{L} 11672$ & 2 & $\uparrow$ \\
\hline Homeo box $\mathrm{C} 1$ protein & M16937 & 2 & $\uparrow$ \\
\hline Sterol regulatory element-binding protein (CNBP) & M28372 & 2 & $\uparrow$ \\
\hline Transcription factor ZFM1, alternatively spliced & D26121 & 2 & $\uparrow$ \\
\hline Zinc finger protein homologous to ZFP-36 in mouse & M92843 & 2 & $\downarrow$ \\
\hline GATA-binding protein 2 (GATA-2) & M68891 & 1 and 2 & $\uparrow$ \\
\hline \multicolumn{4}{|c|}{$\begin{array}{l}\text { Cell receptors, interleukin and interferon receptors, hormone receptors, } \\
\text { neurotransmitter receptors, cell surface antigens and adhesion }\end{array}$} \\
\hline Protein-tyrosine kinase receptor ERBB-3 & M29366 & 2 & $\downarrow$ \\
\hline Interleukin-5 receptor $\alpha$ chain & M75914 & 2 & $\downarrow$ \\
\hline Corticotropin-releasing factor receptor & X72304 & 2 & $\downarrow$ \\
\hline Intercellular adhesion molecule-1 (ICAM-1) & J03132 & 1 and 2 & $\uparrow$ \\
\hline \multicolumn{4}{|c|}{$\begin{array}{l}\text { Extracellular cell signalling and communication proteins, interleukins } \\
\text { and interferons, hormones }\end{array}$} \\
\hline Placental ribonuclease inhibitor (RAI) & M36717 & 1 & $\uparrow$ \\
\hline Hepatoma-derived growth factor & D16431 & 2 & $\uparrow$ \\
\hline Placental growth factor (P1GF) & $\times 54936$ & 2 & $\uparrow$ \\
\hline Glucose-6-phosphate isomerase (neuroleukin) & K03515 & 2 & $\uparrow$ \\
\hline Interleukin 10 (IL-10) & M57627 & 2 & $\uparrow$ \\
\hline Acyl-CoA-binding protein & M14200 & 2 & $\uparrow$ \\
\hline Interleukin $1 \beta$ (IL-1) & K02770 & 2 & $\uparrow$ \\
\hline Insulin-like growth factor-binding protein 1 & M31145 & 2 & $\downarrow$ \\
\hline Vascular endothelial growth factor (VEGF) & M32977 & 2 & $\downarrow$ \\
\hline Interleukin 13 & L06801 & 2 & $\downarrow$ \\
\hline
\end{tabular}

$\uparrow$, Genes up regulated; $\downarrow$, genes down regulated. * Study 1 , genes differentially expressed in HT29 cells treated for $5 \mathrm{~h}$ with 2 mM-butyrate in the presence of $36 \mu \mathrm{M}$-cycloheximide (Della Ragione et al. 2001); study 2, genes differentially expressed in HT29 cells treated for $72 \mathrm{~h}$ with $4 \mathrm{mM}-$ butyrate (lacomino et al. 2001).

\section{Applying the proteomics approach}

Tan et al. (2002) used proteomics to help elucidate the mechanism of action of butyrate in colonocytes. Total cell lysates from HT29 cells treated with or without butyrate ( $5 \mathrm{mM}$ for $24 \mathrm{~h}$ ) were analysed by two-dimensional gel electrophoresis. The gel resolved over 1000 proteins, and comparison of the gels derived from butyrate-treated and control cells revealed regions of the gel showing differential protein expression patterns. MALDI-TOF MS was then used to identify thirty-five of the differentially-expressed spots. The proteins were found to be predominantly of cytosolic or mitochondrial origin. The authors reviewed the putative functions of many of the proteins differentially expressed in relation to butyrate and observed that, in addition to altered expression of proteins involved in the cell cycle, apoptosis and transcriptional regulation (the usual suspects), there was also altered expression of components of the ubiquitin-proteasome system. Tan et al. (2002) hypothesised that butyrate may play a role in regulation of these fundamental cell processes by altered proteolysis of ubiquitinated cellular proteins. For example, it is known that expression of $\mathrm{p} 21^{\mathrm{Waf} 1 / \mathrm{Cip} 1}$ (involved in butyrate-mediated $\mathrm{G}_{0}-\mathrm{G}_{1}$ arrest) shows proteosome-dependent regulation (Blagosklonny et al. 1996).

\section{Conclusions and future developments}

These studies demonstrate how transcriptomic and proteomic experiments can help to elucidate the mechanisms underlying the chemo-preventative properties of butyrate. This work is in its infancy and, given the considerable differences in experimental protocol (e.g. cell line, dose of butyrate, time of exposure, level of expression (mRNA $v$. protein)) used by the different authors, it is unsurprising that there are marked differences in the genes identified as being differentially expressed. However, there is consistent evidence of suppression of CRC cell growth and enhancement of apoptosis, with growing support for the hypothesis that inhibition of histone deacetylation is the probable first step in the molecular action of butyrate.

Expression profiling at the mRNA and protein levels is now established and it offers a powerful route to increased understanding of mechanisms underlying the anti-neoplastic effects of butyrate and other food-derived agents. Rather than focusing on one or a small handful of specific genes or proteins (often chosen largely for pragmatic reasons), transcriptomic and proteomic approaches allow us to consider all the genes transcribed in a cell at a given instant. The challenges are to design protocols that maximise the interpretable information from such studies and to use these data to develop and test specific mechanistic hypotheses. 


\section{Acknowledgement}

J.M.C. thanks the BBSRC for a research studentship.

\section{References}

Anderson L \& Seilhamer J (1997) A comparison of selected mRNA and protein abundances in human liver. Electrophoresis 18, 533-537.

Andoh A, Shimada M, Araki Y, Fujiyama Y \& Bamba T (2002) Sodium butyrate enhances complement-mediated cell injury via down-regulation of decay-accelerating factor expression in colonic cancer cells. Cancer Immunology and Immunotherapy 50, 663-672.

Armstrong F \& Mathers JC (2000) Kill and cure: dietary augmentation of immune defences against colon cancer. Proceedings of the Nutrition Society 59, 215-220.

Ballestar E \& Esteller M (2002) The impact of chromatin in human cancer: linking DNA methylation to gene silencing. Carcinogenesis 23, 1103-1109.

Bingham SA (1990) Mechanisms and experimental and epidemiological evidence relating dietary fibre (non-starch polysaccharides) and starch to protection against large bowel cancer. Proceedings of the Nutrition Society 49, 153-171.

Blackstock WP \& Weir MP (1999) Proteomics: quantitative and physical mapping of cellular proteins. Trends in Biotechnology 17, 121-127.

Blagosklonny MV, Wu GS, Omura S \& el-Deiry WS (1996) Proteasome-dependent regulation of p21WAF1/CIP1 expression. Biochemical and Biophysical Research Communications 227, 564-569.

Bonnotte B, Favre N, Reveneau S, Micheau O, Droin N, Garrido C, Fontana A, Chauffert B, Solary E \& Martin F (1998) Cancer cell sensitization to Fas-mediated apoptosis by sodium butyrate. Cell Death and Differentiation 5, 480-487.

Browne SJ, Macfarlane M, Cohen GM \& Paraskeva C (1998) The adenomatous polyposis coli protein and retinoblastoma proteins are cleaved early in apoptosis and are potential substrates for caspases. Cell Death and Differentiation 5, 206-213.

Browne SJ, Williams AC, Hague A, Butt AJ \& Paraskeva C (1994) Loss of APC protein expressed by human colonic epithelial cells and the appearance of a specific low-molecular-weight form is associated with apoptosis in vitro. International Journal of Cancer 59, 56-64.

Butt AJ, Hague A \& Paraskeva C (1997) Butyrate- but not TGF $\beta_{1^{-}}$ induced apoptosis of colorectal adenoma cells is associated with increased expression of the differentiation markers E-cadherin and alkaline phosphatase. Cell Death and Differentiation 4, 725-734.

Chai F, Evdokiou A, Young GP \& Zalewski PD (2000) Involvement of $\mathrm{p} 21^{\text {Waf } 1 / \text { Cip1 } 1}$ and its cleavage by DEVD-caspase during apoptosis of colorectal cancer cells induced by butyrate. Carcinogenesis 21, 7-14.

Clarke KO, Feinman R \& Harrison LE (2001) Tributyrin, an oral butyrate analogue, induces apoptosis through activation of caspase-3. Cancer Letters 171, 57-65.

Cummings JH, Pomare EW, Branch WJ, Naylor CP \& Macfarlane GT (1987) Short chain fatty acids in human large intestine, portal, hepatic and venous blood. Gut 28, 1221-1227.

D'Anna JA, Tobey RA \& Gurley LR (1980) Concentrationdependent effects of sodium butyrate in Chinese hamster cells: cell cycle progression, inner-histone acetylation, histone $\mathrm{H} 1$ dephosphorylation, and induction of an H1-like protein. Biochemistry 19, 2656-2671.

D'Argenio G, Cosenza V, Delle Cave M, Iovino P, Della Valle N, Lombardi G \& Mazzacca G (1996) Butyrate enemas in experimental colitis and protection against large bowel cancer in a rat model. Gastroenterology 110, 1727-1734.

Della Ragione F, Criniti V, Della Pietra V, Borriello A, Oliva A, Indaco S, Yamamoto T \& Zappia V (2001) Genes modulated by histone acetylation as new effectors of butyrate activity. FEBS Letters 499, 199-204.

Diakos C, Prieschl EE, Saemann M, Novotny V, Bohmig G, Csonga R, Baumruker T \& Zlabinger GJ (2002) Novel mode of interference with nuclear factor of activated T-cells regulation in T-cells by the bacterial metabolite $n$-butyrate. Journal of Biological Chemistry 277, 24243-24251.

Duggan DJ, Bittner M, Chen Y, Meltzer P \& Trent JM (1999) Expression profiling using cDNA microarrays. Nature Genetics 21, 10-14.

Evan G \& Littlewood T (1998) A matter of life and cell death. Science 281, 1317-1322.

Faust D, Hormann S, Friedrich-Sander M, Milovic V \& Stein J (2001) Butyrate and the cytokine-induced alpha1-proteinase inhibitor release in intestinal epithelial cells. European Journal of Clinical Investigation 31, 1060-1063.

Gamet L, Daviaud D, Denis-Pouxviel C, Remesy C \& Murat JC (1992) Effects of short-chain fatty acids on growth and differentiation on the human colon-cancer cell line HT-29. International Journal of Cancer 52, 286-289.

Giermasz A, Makowski M, Nowis D, Jalili A, Maj M, Dabrowsks A, Czajka A, Jakobisiak M \& Golab J (2002) Potentiated antitumour effects of butyrate and actinomycin D in melanoma model in mice. Oncology Reports 9, 199-203.

Hacia JG \& Collins FS (1999) Mutational analysis using oligonucleotide microarrays. Journal of Medical Genetics 36, 730-736.

Hague A, Manning AM, Hanlon KA, Huschtscha LI, Hart D \& Paraskeva C (1993) Sodium butyrate induces apoptosis in human colonic tumour cell lines in a p53-independent pathway: implications for the possible role of dietary fibre in the prevention of large-bowel cancer. International Journal of Cancer 55, 498-505.

Hanahan D \& Weinberg RA (2000) The hallmarks of cancer. Cell 100, $57-70$.

Heerdt BG, Houston MA \& Augenlicht LH (1994) Potentiation by specific short-chain fatty acids of differentiation and apoptosis in human colonic carcinoma cell lines. Cancer Research 54, 3288-3294.

Iacomino G, Tecce M, Grimaldi C, Tosto M \& Russo GL (2001) Transcriptional response of a human colon adenocarcinoma cell line to sodium butyrate. Biochemical and Biophysical Research Communications 285, 1280-1289.

Inan MS, Rasoulpour RJ, Yin L, Hubbard AK, Rosenberg DW \& Giardina C (2000) The luminal short-chain fatty acid butyrate modulates NF-kappaB activity in a human colonic epithelial cell line. Gastroenterology 118, 724-734.

Jones MB, Krutzsch H, Shu H, Zhao Y, Liotta LA, Kohn EC \& Petricoin EF (2002) Proteomic analysis and identification of new biomarkers and therapeutic targets for invasive ovarian cancer. Proteomics 2, 76-84.

Jordan NJ, Kolios G, Abbot SE, Sinai MA, Thompson DA, Petraki K \& Westwick J (1999) Expression of functional CXCR4 chemokine receptors on human colonic epithelial cells. Journal of Clinical Investigation 104, 1061-1069.

Kiess M, Gill RM \& Hamel PA (1995) Expression of the positive regulator of cell cycle progression, cyclin D3, is induced during differentiation of myoblasts into quiescent myotubules. Oncogene 10, 159-166.

Kitahara O, Furukawa Y, Tanaka T, Kilhara C, Ono K, Yanagawa R, Nita ME, Takagi T, Nakamura Y \& Tsunoda T (2001) Alterations of gene expression during colorectal carcinogenesis 
revealed by cDNA microarrays after laser-capture microdissection of tumor tissues and normal epithelia. Cancer Research 61, 3544-3549.

Klose J (1999) Large-gel 2-D electrophoresis. Methods in Molecular Biology 112, 147-172.

Kruh J (1982) Effects of sodium butyrate, a new pharmacological agent, on cells in culture. Molecular and Cellular Biochemistry 42, 65-82.

Kruh J, Defer N \& Tichonicky L (1995) Effects of butyrate on cell proliferation and gene expression. In Physiological and Clinical Aspects of Short-chain Fatty Acids, pp. 275-288 [JH Cummings, JL Rombeau and T Sakata, editors]. Cambridge: Cambridge University Press.

Leder A \& Leder P (1975) Butyric acid, a potent inducer of erythroid differentiation in cultured erythroleukemic cells. Cell 5, 319-322.

Liu Y \& Kulesz-Martin M (2001) p53 protein at the hub of cellular DNA damage response pathways through sequence-specific and non-sequence-specific DNA binding. Carcinogenesis 22, $851-860$.

Luo J, Duggan DJ, Chen Y, Sauvageot J, Ewing CM, Bittner ML, Trent JM \& Isaacs WB (2001) Human prostate cancer and benign prostatic hyperplasia: molecular dissection by gene expression profiling. Cancer Research 61, 4683-4688.

Mahyar-Roemer M \& Roemer K (2001) p21 Waf1/Cip1 can protect human colon carcinoma cells against p53-dependent and p53-independent apoptosis induced by natural chemopreventive and therapeutic agents. Oncogene 20, 3387-3398.

Mariadason J, Corner GA \& Augenlicht LH (2000) Genetic reprogramming in pathways of colonic cell maturation induced by short chain fatty acids: Comparison with trichostatin A, sulindac, and curcumin and implications for chemoprevention of colorectal cancer. Cancer Research 60, 4561-4572.

Mohr S, Leikauf GD, Keith G \& Rihn BH (2002) Microarrays as cancer keys: an array of possibilities. Journal of Clinical Oncology 20, 3165-3175.

Nancey S, Bienvenu J, Coffin B, Andre F, Decos L \& Flourie B (2002) Butyrate strongly inhibits in vitro stimulated release of cytokines in blood. Digestive Diseases and Sciences 47, 921-928.

O'Farrell PH (1975) High resolution two-dimensional electrophoresis of proteins. Journal of Biological Chemistry 250, 4007-4021.

Pellizzaro C, Coradini D \& Daidone GG (2002) Modulation of angiogenesis-related proteins synthesis by sodium butyrate in colon cancer cell line HT29. Carcinogenesis 23, 735-740.

Perrin P, Cassagnau E, Burg C, Party Y, Vavasseur F, Harb J, Le Pendu J, Douillard J-Y, Galmiche J-P, Bornet F \& Meflah K (1994) An interleukin 2/sodium butyrate combination as immunotherapy for rat colon cancer peritoneal carcinomatosis. Gastroenterology 107, 1397-1408.

Prasad KN \& Sinha PK (1976) Effect of sodium butyrate on mammalian cells in culture. In Vitro 12, 125-132.

Ruemmele FM, Dionne S, Qureshi I, Sarma DSR, Levy E \& Seidman EG (1999) Butyrate mediates Caco-2 cell apoptosis via up-regulation of pro-apoptotic BAK and inducing caspase-3 mediated cleavage of poly-(ADP-ribose) polymerase (PARP). Cell Death and Differentiation 6, 729-735.

Saemann MD, Bohmig GA, Osterreicher CH, Burtscher H, Parolini O, Diakos C, Stockl J, Horl WH \& Zlabinger GJ (2000) Antiinflammatory effects of sodium butyrate on human monocytes: potent inhibition of IL-12 and up-regulation of IL-10 production. FASEB Journal 14, 2380-2382.
Saemann MD, Parolini O, Bohmig GA, Kelemen P, Krieger PM, Neumuller J, Kanrr K, Kammlaander W, Horl WH, Diakos C, Stuhlmeier K \& Zlabinger GJ (2002) Bacterial metabolite interference with maturation of human monocyte-derived dendritic cells. Journal of Leukocyte Biology 71, 238-246.

Sapolsky RJ, Hsie L, Berno A, Ghandour G, Mittmann M \& Fan JB (1999) High-throughput polymorphism screening and genotyping with high-density oligonucleotide arrays. Genetic Analysis 14, 187-192.

Schwartz B, Avivi-Green C \& Polak-Charcon S (1998) Sodium butyrate induces retinoblastoma protein dephosphorylation, p16 expression and growth arrest of colon cancer cell. Molecular and Cellular Biochemistry 188, 21-30.

Siavoshian S, Blottière HM, Le Foll E, Kaeffer B, Cherbut C \& Galmiche JP (1997) Comparison of the effect of different short chain fatty acids on the growth and differentiation of human colonic carcinoma cell lines in vitro. Cell Biology International 21, 281-287.

Siavoshian S, Segain J-P, Kornprobst M, Bonnet C, Cherbut C, Galmiche J-P \& Blottière HM (2000) Butyrate and trichostatin A effects on the proliferation/differentiation of human intestinal epithelial cells: induction of cyclin D3 and p21 expression. Gut 46, 507-514.

Southern E, Mir K \& Shchepinov M (1999) Molecular interactions on microarrays. Nature Genetics 21, 5-9.

Steinbach G, Lynch PM, Phillips RK, Wallace MH, Hawk E, Gordon GB, Wakabayashi N, Saunders B, Shen Y, Fujimura T, Su LK \& Levin B (2000) The effect of celecoxib, a cyclooxygenase-2 inhibitor, in familial adenomatous polyposis. New England Journal of Medicine 342, 1946-1952.

Steinman RA, Hoffman B, Iro A, Guillouf C, Libermann DA \& elHouseini ME (1994) Induction of p21 (WAF-1/CIP1) during differentiation. Oncogene 9, 3389-3396.

Tan S, Seow TK, Liang RC, Koh S, Lee C, Chung M \& Hooi S (2002) Proteome analysis of butyrate-treated human colon cancer cells (HT29). International Journal of Cancer 98, 523-531.

Van Eyk JE (2001) Proteomics: unraveling the complexity of heart disease and striving to change cardiology. Current Opinion in Molecular Therapeutics 3, 546-553.

Wasinger VC, Cordwell SJ, Cerpa-Poljak A, Yan JX, Gooley AA, Wilkins MR, Duncan MW, Harris R, Williams KL \& HumpherySmith I (1995) Progress with gene-product mapping of the Mollicutes: Mycoplasma genitalium. Electrophoresis 16, 1090-1094.

Webb SJ, Nicholson D, Bubb VJ \& Wyllie AH (1999) Caspasemediated cleavage of APC results in an amino-terminal fragment with an intact armadillo repeat domain. FASEB Journal 13, 339-346.

Weinberg RA (1995) The retinoblastoma protein and cell cycle control. Cell 81, 323-330.

Whitehead RH, Young GP \& Bhathal PS (1986) Effects of short chain fatty acids on a new human colon carcinoma cell line (LIM 1215). Gut 27, 1457-1463.

Wintersberger E, Mudrak I \& Wintersberger U (1983) Butyrate inhibits mouse fibroblasts at a control point in the $\mathrm{G}_{1}$ phase. Journal of Cellular Biochemistry 21, 239-247.

World Cancer Research Fund and the American Institute of Cancer Research (1997) Food, Nutrition and the Prevention of Cancer: a Global Perspective. Washington, DC: World Cancer Research Fund and the American Institute of Cancer Research. 